\title{
What could happen in a Monetary Union? The Perspective of Informational Asymmetry
}

\author{
Cornel Oros \\ CRIEF, Université de Poitiers and LEO, Université d'Orléans
}

\begin{abstract}
The subsidiarity principle governing the collection of statistical data in a monetary union may result in asymmetrical information. The national governments may be tempted to distort their economic and financial data communicated to the union's central bank in order to influence its monetary policy decisions. We base our analysis on a static Keynesian model in a closed monetary union and we prove that the governments' incentives to modify their private information depend mainly on the nature of the economic shocks affecting the union members, on the degree of monetary activism, and on the extent of the union's structural heterogeneity. We analyse the institutional mechanisms that could be used to discipline the governments and encourage them to communicate real information. An incentive contract of the "principal-agent" type or a variable geometry fiscal coordination represent two institutional solutions that could help to create a revealing equilibrium within a monetary union.
\end{abstract}

JEL Classifications: E52, E58, E61, E62, E63

Key Words: Economic Policy, Asymmetrical Information, Economic Shocks, Structural Heterogeneity

\footnotetext{
* Corresponding Author: Cornel Oros; CRIEF-University of Poitiers and LEO-University of Orléans, 2, Rue Jean Carbonnier Bat A1 (BP 623), 86022 Poitiers, France, Tel: (33) 05492875 51, Fax: (33) 05494541 58, Email: cornel.oros@univ-poitiers.fr.

Acknowledgments: I thank Leila Ali, Christian Aubin, Jean-Marc Bascans, Jens Klose, Janique Penisson, Dominique Pépin, Christian Richter, Blandine Zimmer as well as the participants to the $12^{\text {th }}$ INFER Annual Conference for their constructive comments on a previous version of this paper. I also thank an anonymous referee and the Editor, Professor, Jong Eun Lee for their comments and suggestions which helped me improve this paper.
} 


\section{Introduction}

Since the creation of the Euro zone, the question of the policy-mix in a monetary union has been dealt with according to two main issues. The first one is the issue of credibility concerning the combination of economic policies and involves possible discrepancies relative to macroeconomic objectives between the national governments and the single central bank ${ }^{1}$. The second issue is concerned with macroeconomic stabilization in response to different types of shocks that can affect the economies of the member countries in a specific institutional context, which is that of the independence of the ECB and of the fiscal constraints imposed on the governments by the Stability and Growth Pact $2^{2}$.

These two major issues trigger another problematic aspect specific to monetary unions, which is the asymmetrical information that may appear among the policymakers and thus influence the organization of the policy-mix. A type of asymmetrical information specific to monetary unions could arise from the fact that the governments have private information about their economic shocks which they may choose either to hide or to transmit in a deformed manner to the other governments and to the central bank in order to enhance their individual welfare. Considering the institutional organization of a monetary union, this asymmetrical information can be accounted for in two ways. Firstly, the governments can have a certain influence on national statistical information. Indeed, despite measures of control and harmonisation that can be put in place, statistical data are essentially collected by the national institutes $^{3}$ which, despite their official independence, can be subject to pressure from the governments. For instance, in the case of the EMU, the Greek case is a significant example: the government was able to deliberately tamper with the statistics of public accounts without any reaction from its partners or the European institutions ${ }^{4}$. There is currently no guarantee that other countries won't adopt similar deceitful behaviour, all the more so since the Euro zone is likely to become even more heterogeneous with its enlargement to the CEECs.

Secondly, when deciding on a single monetary policy, the union's central bank takes into account the aggregate values of macroeconomic variables at the level of the entire monetary union, ${ }^{6}$ which can encourage countries to distort the information given to the union's central

\footnotetext{
${ }^{1}$ See Dixit and Lambertini (2001), Beetsma and Bovenberg (1998, 1999), Beetsma and Uhlig (1999), Chari and Kehoe (1998), Dornbusch (1997), Villieu (2003).

${ }^{2}$ See Uhlig (2002), Mundschenk and Von Hagen (2003), Beetsma et al. (2001), Engwerda et al. (2002).

${ }^{3}$ This is based on the subsidiary principle in collecting and transmitting statistical data.

${ }^{4}$ Greece falsified its statistics relative to its public deficit and its public debt for 2009

5 In fact, over the last few years, in addition to the Greek case, the European Commission has also questioned the quality of Italy's and Portugal's economic and financial statistics. There seems to be a constant tendency of governments being tempted to distort their statistics and to put pressure on the national statistics institutes irrespective of the type of data involved. For example, there have been recent allegations in the media about distortion of unemployment information in France and Germany (Mathieu (2009) and Meillassoux (2011)

${ }^{6}$ The EMU is the most representative example. The ECB makes its monetary policy decisions based on the evolution of aggregate
} 
bank even more so that the bank's policy would become oriented according to their specific objectives. For instance, by overestimating the extent of its demand shock, a country could avoid compensation of the shocks' effects at the aggregate level of the union. This is indeed the only means for a country to generate a stabilization effort from the central bank in order to stabilize its national variables.

So far, very few studies have discussed the European policy-mix in a case of asymmetrical information. Their main conclusion points out the lack of effectiveness of a decentralized system of collecting economic and financial information on account of the union countries' inclination to modify their information in order to influence the ECB's decisions. This lack of effectiveness is, however, linked with heterogeneities existing within the EMU either at the level of the policymakers' objectives (Crettez (1998)) or at the level of economic shocks (Bottazzi and Manasse (2005), Duchassaing and Koessler (2004)). Inexact information provided by the governments may generate inflation and public deficit bias as well as excessively restrictive monetary policy and recession bias (Bottazzi and Manasse (1998, 2005)). Yet, Duchassaing and Koessler (2004) show that the governments could be prevented from changing their private information by a fiscal leadership configuration in which the transmission of information is expensive. But when the information about national shocks is correct, there is a loss in terms of welfare at the national level compared to a simultaneous policy game, which dissuades fiscal authorities from adopting such a policy-mix configuration.

Based on the literature on the subject, this paper aims at further exploring this issue by analysing the impact of asymmetrical information on the effectiveness of economic policies within a heterogeneous monetary union. As the member countries have private information on their specific shocks, we want to point out that the governments have an interest in changing this private information that will then be provided to the central bank. Several questions will thus be addressed: which are the mechanisms that account for the governments' changing their statistical data? Is this behaviour systematic? What are the institutional means that would allow from discipline of the governments and prevent them from providing modified data? In other words, we will analyse the reliability of the subsidiarity principle in collecting statistical data and the adjustment possibilities of this principle in order to avoid the governments being tempted to modify their national statistical data.

In the first section of the paper, we will present a model which accounts for macroeconomic equilibrium and the reaction functions of the policymakers (the national governments and the central bank). In the second part, we will look into the reasons why the governments are tempted to distort their private information. In the last section, we will analyse some of the mechanisms that could allow for discipline of the fiscal authorities in order to avoid information alternation.

\footnotetext{
variables at the level of the Euro zone at large.

In a monetary union, the single monetary policy doesn't take into account national asymmetric shocks since their effects are compensated at the aggregate level.
} 


\section{A. The Model}

We use a static Keynesian model within a closed monetary union of two countries $(i, j)$. We have deliberately chosen a very simple model in order to be able to focus on the analysis of the mechanisms used by the governments in transmitting their private information about national economic shocks in the case of asymmetric information among the policymakers within the union. Macroeconomic equilibriums are described by demand and supply functions and we consider that the heterogeneity of the union involves both the mechanisms of monetary policy transmission and the economic shocks affecting the union members (Oros (2008a)). All the variables (except the interest rate) are expressed as logarithms. Thus the demand function is represented by a standard IS function, often used in the literature:

$$
y_{i}=a g_{i}+b g_{j}-\delta_{i} r+\varepsilon_{i} \text { where } 0<a<1 ; b<1 ; \delta>0
$$

$y_{i}$ and $g_{i}$ stand for output (as deviation from the natural output) and the budget deficit of the country $i ; g_{j}$ represents the budget deficit of the country $j ; r$ represents the short-term interest rate; $\varepsilon_{i}$ the demand shock specific to country $i$ with zero mean and finite variance $\sigma_{\varepsilon_{i}}^{2}$. The demand shocks $\left(\varepsilon_{i}, \varepsilon_{j}\right)$ are independent random variables whose density functions are expressed by normal distributions with zero mean.

The national demand of the country $i$ depends positively on its national budget deficit according to a sensitivity below the unit $(a<1)$ because of the crowding out effect, and depends negatively on the interest rate according to sensitivity $\delta$. At the same time, the national output of country $i$ is influenced by the budget deficit of the other union member in a proportion $b$. The sign of the parameter $b$ can be positive or negative according to whether it is the output channel or the common interest rate channel, respectively, that play the major part in the transmission of the fiscal spillovers. Finally, the national output is influenced by a specific demand shock.

Since the heterogeneity of the Union is relevant to the mechanisms of monetary policy transmission, the parameter $\delta$ is specific to each country. If we represent the degree of heterogeneity between countries by a coefficient $h(0<h<1)$, then $\delta_{i}=(1+h) \delta$ and $\delta_{j}=(1-h)$ $\delta$, where $\delta$ stands for the average impact of monetary policy on the economic activity of the countries $i$ and $j$. Therefore, if $h=0$, the countries will be perfectly homogeneous in terms of monetary policy transmission mechanisms $\left(\delta_{i}=\delta_{j}\right)$, whereas, if $h=1$, the heterogeneity between the two countries attains its maximum degree, as monetary policy influences exclusively and with a maximum impact the national demand of country $i\left(\delta_{i}=2 \delta\right.$ and $\left.\delta_{j}=0\right)$.

Regarding the supply equation, we use a Lucas function. We consider that the expected inflation is zero as we are only investigating the issue of the macroeconomic stabilization and therefore leave aside any issue of credibility.

$$
\pi_{i}=\mu y_{i} \quad \text { where } \quad \mu>0
$$


$\pi_{i}$ represents the inflation of country $i$. For any variable $x$, we define the aggregate component, $x=\left(x_{i}+x_{j}\right) / 2$ and the difference component, $\bar{x}=\left(x_{i}-x_{j}\right) / 2$. Regarding shocks, we consider $\varepsilon$ and $\bar{\varepsilon}$ which stand for symmetric and asymmetric shocks, respectively.

Having described the macroeconomic framework, we will now analyse the behaviour of the policy-makers. The central bank decides on a single monetary policy independently, using its interest rate as a policy instrument in order to minimize its loss function $\left(L^{M}\right)$. The central bank is mainly interested in price stabilization at the aggregate level of the union (with a weight $\beta_{0}$ ), but also in interest rate smoothing (with a weight $\beta_{2}$ ). ${ }^{8}$

$$
L^{M}=\frac{1}{2}\left[\beta_{0} \pi^{2}+\beta_{2} r^{2}\right] \quad \text { where } \quad \beta_{0}, \beta_{2}>0
$$

The governments are in charge of the implementation of fiscal policies using the budget deficit as a policy instrument. Their aim is to minimize a loss function $\left(L_{i}^{G}\right)$ which depends on the evolution of their country's national output and budget deficit (the relative weight of these objectives is $\alpha_{1}$ et de $\alpha_{2}$ respectively).

$$
L_{i}^{G}=\frac{1}{2}\left[\alpha_{1} y_{i}^{2}+\alpha_{2} g_{i}^{2}\right] \quad \text { where } \quad \alpha_{1}, \alpha_{2}>0
$$

We will first present the values of the policy instruments in a complete information game; we will then use these values to identify the macroeconomic equilibrium in a case of asymmetrical information. The players are aware of the shocks affecting the member countries before the beginning of the simultaneous and non-cooperative game (Nash equilibrium). In this configuration, the interest rate, the aggregate, and the difference component of budget deficit are written as follows:

$$
\left\{\begin{array}{l}
r=\frac{z[(a+b) g+\varepsilon]}{\delta} \\
g=\frac{a \alpha_{1}(\delta r-\varepsilon)}{A} \\
\bar{g}=\frac{a \alpha_{1}(\delta h r-\bar{\varepsilon})}{\alpha_{2}+a \alpha_{1}(a-b)} \quad \text { with } \quad z=\frac{\beta_{0} \mu^{2}}{\beta_{0} \mu^{2}+\frac{\beta_{2}}{\delta^{2}}}, A=\alpha_{2}+a \alpha_{1}(a+b)
\end{array}\right.
$$

Using the equations (5) the equilibrium values of the budget deficit and the interest rate become:

$$
\left\{\begin{array}{l}
g=-\frac{a \alpha_{1}(1-z)}{D} \varepsilon \\
\bar{g}=\frac{a \alpha_{1} \alpha_{2} z h}{D C} \varepsilon-\frac{a \alpha_{1}}{C} \bar{\varepsilon} \\
r=\frac{z \alpha_{2}}{\delta D} \varepsilon \quad \text { with } \quad D=\alpha_{2}+a \alpha_{1}(a+b)(1-z), C=\alpha_{2}+a \alpha_{1}(a-b)
\end{array}\right.
$$

\footnotetext{
${ }^{8}$ The target values of the macroeconomic variables in the policy-makers' loss functions are normalized to zero
} 
The equations (6) show that for a specific demand shock, the stabilization efforts made by the governments affected by this shock and by the central bank converge. For instance, in the case of a negative demand shock affecting country $i$, its government and the central bank will adopt an expansionary policy; the budget deficit will rise while the interest rate will go down in order to encourage demand and to boost activity.

Moreover, it can be noticed that the central bank's reaction is determined by the average demand shock of the union. Consequently, if the demand shocks are asymmetric, every government may be inclined to overestimate their shocks so that the central bank will adapt its monetary policy in favour of each government's specific objective.

We can intuitively posit that convergence of the stabilisation efforts made by the governments and the central bank can account for the temptation for the fiscal authorities to modify their messages to the central bank. Indeed, as fiscal reaction is expensive (the evolution of the budget deficit is an element of loss functions for the governments), giving false information could strengthen monetary activism and thus allow the governments to loosen their efforts in the stabilisation process with a positive effect in terms of welfare.

\section{B. The Governments' Strategies of Communicating Private Information}

We examine the case of an incomplete information game, which means that there is an information gap between the players in which the governments have private information about their economic shocks. The game configuration will therefore be a Bayesian game in which each player knows the density function of the shocks. The governments' and the central bank's decisions are taken simultaneously and non-cooperatively.

Based on the subsidiarity principle in collecting and transmitting statistical data in a monetary union, we consider that each government accepts ex-ante to inform the central bank about the exact nature and extent of its national shock. Formally, the commitment of government $i$ is written as: $\theta_{i}=\varepsilon_{i}$, where $\theta_{i}$ represents the message transmitted by government $i$ to the central bank when shock $\varepsilon_{i}$ occurs. After this stage, the simultaneous game will be put into place and each player's optimal decisions will be identified. We consider also that, contrary to the central bank, the governments have exact information about the specific shocks affecting the union's members countries and we examine the unilateral incentive of the governments to fail to live up to their commitments and to transmit a distorted message $\left(\underline{\theta}_{i}\right.$ where $\left.\underline{\theta}_{i} \neq \varepsilon_{i}\right)$ to the central bank.

The hypothesis that the union member countries have mutual knowledge of their specific shocks is based on the specificity of the economic and institutional context in a monetary union.

\footnotetext{
In the case of symmetric shocks, the convergence of stabilization efforts concerns all the public authorities (the governments and the central bank). Moreover, when , the central bank can use its policy instrument freely and it manages to perfectly absorb the impact of the symmetric shocks.
} 
Firstly, a monetary union is likely to be characterized by a high degree of economic and financial integration that makes the countries' business cycles extremely dependent on one another. It is therefore very likely that each country can obtain exact information about the shocks affecting the other members of the union and that, at the same time, it would be particularly difficult for a country to conceal or distort the state of its economy when faced with the other countries.

Secondly, what justify the hypothesis that every country is aware of the situation of their economic partners are the institutional features of a monetary union and its economic governance. If the governments inform one another about economic shocks while still having an informational advantage over the single central bank, they would be able to have more flexibility in stabilizing their economic situations especially in the case of rigid economic governance which constraints the governments' actions against economic shocks. Modifying data transmitted to the Union Central Bank may be a way for the governments to find a further means to fight against the economic shocks and thus stabilize their national macroeconomic variables. Indeed, by modifying their message to the single central bank, the fiscal authorities gear the union's monetary policy towards their specific objectives of macroeconomic stabilization.

Moreover, the hypothesis that informational discrepancy can only occur between the governments and the central bank is reinforced by the results of a complete informational model, which we have previously introduced. Indeed, as we have already pointed out, as the governments' and the central bank's efforts for stabilization converge, the governments may well be tempted to distort their messages to the monetary authority.

Based on the hypothesis that the member countries are aware of the shocks affecting the union and assuming that country $i$ tries to deviate from its commitment of conveying true information to the central bank, we can identify the new game equilibrium. Thus, the central bank establishes its optimum interest rate based on the information about the economic shocks provided by the governments $\left(\underline{\theta}_{i}\right.$ and $\left.\varepsilon_{j}\right)$ :

$$
r=\frac{z}{\delta}\left[(a+b) g+\underline{\theta}_{i}+\varepsilon_{j}\right]
$$

In this game configuration, the aggregate and the difference components of public deficit $\operatorname{are}^{10}$ :

\footnotetext{
${ }^{10}$ The complete equations are available upon request.
} 


$$
\left\{\begin{array}{l}
g=\frac{a \alpha_{1}}{A}\left[\frac{\alpha_{2} z}{D}\left(\underline{\theta}_{i}+\varepsilon_{j}\right)-\left(\varepsilon_{i}+\varepsilon_{j}\right)\right] \\
\bar{g}=\frac{a \alpha_{1}}{C}\left[\frac{\alpha_{2} z h}{D}\left(\underline{\theta}_{i}+\varepsilon_{j}\right)-\left(\varepsilon_{i}-\varepsilon_{j}\right)\right] \\
y=-\frac{\alpha_{2}}{A}\left[\frac{\alpha_{2} z}{D}\left(\underline{\theta}_{i}+\varepsilon_{j}\right)-\left(\varepsilon_{i}+\varepsilon_{j}\right)\right] \\
\bar{y}=-\frac{\alpha_{2}}{C}\left[\frac{\alpha_{2} z h}{D}\left(\underline{\theta}_{i}+\varepsilon_{j}\right)-\left(\varepsilon_{i}-\varepsilon_{j}\right)\right]
\end{array}\right.
$$

The equilibrium values of the macroeconomic variables will be introduced in government $i$ 's loss function $\left(L_{i}^{G}\right)$. If we minimize this loss function relative to $\underline{\theta}_{i}$, we obtain the optimum message provided by country $i$ :

$$
\underline{\theta}_{i}=\varepsilon_{i}+\frac{\left.A\left[C(1-z)-\alpha_{2} z h\right)\right]}{\alpha_{2} z[C+h A]}\left[\varepsilon_{i}+\varepsilon_{j}\right]+\frac{A D}{\alpha_{2} z[C+h A]}\left[\varepsilon_{i}-\varepsilon_{j}\right]
$$

According to the same principle, we obtain the optimum message provided to the central bank by country $j$ :

$$
\underline{\theta}_{j}=\varepsilon_{j}+\frac{\left.A\left[C(1-z)+\alpha_{2} z h\right)\right]}{\alpha_{2} z[C-h A]}\left[\varepsilon_{i}+\varepsilon_{j}\right]+\frac{A D}{\alpha_{2} z[C-h A]}\left[\varepsilon_{j}-\varepsilon_{i}\right]
$$

The first general observation that we can make regarding optimal messages transmitted by the governments is that the temptation to distort information is not systematic. Thus, the revealing equilibrium (when the two governments announce their true shocks to the central bank) occurs if the central bank is not constrained in using its interest rate $(z=1)$ and if the union is homogeneous both structurally $(h=0)$ and in terms of economic shocks affecting the member countries $\left(\varepsilon_{i}=\varepsilon_{j}\right)$. Indeed, a maximum degree of monetary activism means that the Central Bank has no remaining leeway to stabilize shocks. Consequently, the governments have no reason to distort information about their national shocks if the shocks are symmetrical and if the efforts of stabilization made by the Central Bank are equally profitable to all of the governments. On the contrary, any asymmetry of the level of the national shocks causes every government to distort its private information in order to influence the central bank's decisions regarding monetary policy in favour of its specific objectives.

There is a second general element that influences the strategy of the governments in revealing their private information: it concerns the way in which the central bank organizes its macroeconomic objectives. The governments will be all the more inclined to lie about the extent of economic shocks if the central bank focuses on interest rate smoothing ( $\beta_{2}$ rises) rather than on 
stabilization of inflation ( $\beta_{0}$ falls). In other words and taking into account the fact that both the governments and the central bank have an interest in stabilizing demand shocks, we can state that the less active the central bank is, the more involved the governments become in making up for the central bank's lack of activism by overestimating the extent of their shocks.

The differences between the specific national communication strategies depend on the existence of structural heterogeneity among the union member countries $(h \neq 0)$ and concern both symmetric and asymmetric shocks.

Regarding symmetric shocks $\left(\varepsilon_{i}=\varepsilon_{j}\right)$, in the case of government $i$, we identify a degree of structural heterogeneity $h^{*}$ for which the revealing equilibrium is optimal in terms of national welfare $\left(h^{*}=\frac{C(1-z)}{\alpha_{2} z}\right)$. We can notice that the degree of structural heterogeneity that leads to a revealing equilibrium decreases as $z$ and $\alpha_{2}$ (the government's preference for a stable budget deficit) rise. When $z$ rises - which is justified either by reinforced monetary policy activism ( $\beta_{2}$ decreases and $\beta_{0}$ increases) or by a national demand highly sensitive to the single monetary policy ( $\delta$ increases) - the stabilization effects of monetary policy are more efficiently transmitted and the effects of this increase of $z$ on country $i$ are similar to those of reinforced structural heterogeneity ( $h$ increases) ${ }^{11}$. Therefore, the two coefficients $(z$ and $h$ ) can be substituted for one another. At the same time, if $\alpha_{2}$ increases, the governments will be less interested in stabilizing their national output and country $i$ experiences less demand for high structural heterogeneity as a means of stabilizing its output provided by monetary policy.

The threshold value of structural heterogeneity $\left(h^{*}\right)^{12}$ allows for a distinction between two deceitful behaviours triggered by different causes. When the degree of heterogeneity is inferior to the threshold value it is only the extent of the shock that may be the object of a distorted message. The inclination to do so diminishes when structural heterogeneity is reinforced, whereas when $h>\frac{C(1-z)}{\alpha_{2} z}$, country $i$ will be inclined to communicate a shock of a different type and whose extent is all the more distorted as structural heterogeneity is high (Figure 1).

\footnotetext{
${ }^{11}$ Indeed, the rise of represents an increased $\frac{C(1-z)}{\alpha_{2} z}$ sensitivity of country's national demand to the effects of the single monetary policy.

12 Since the degree of heterogeneity $(h)$ is below the unit, the threshold value has to meet another condition $\left(\frac{C(1-z)}{\alpha_{2} z}<1\right)$. We can identify the threshold value of monetary activism which allows for the above condition: $\cdot \beta_{2}<\frac{\beta_{0} \mu^{2} \alpha_{2} \delta^{2}}{C}$.
} 
Figure 1. Country $i$ 's Informational Bias in the Case of Symmetrical Shocks

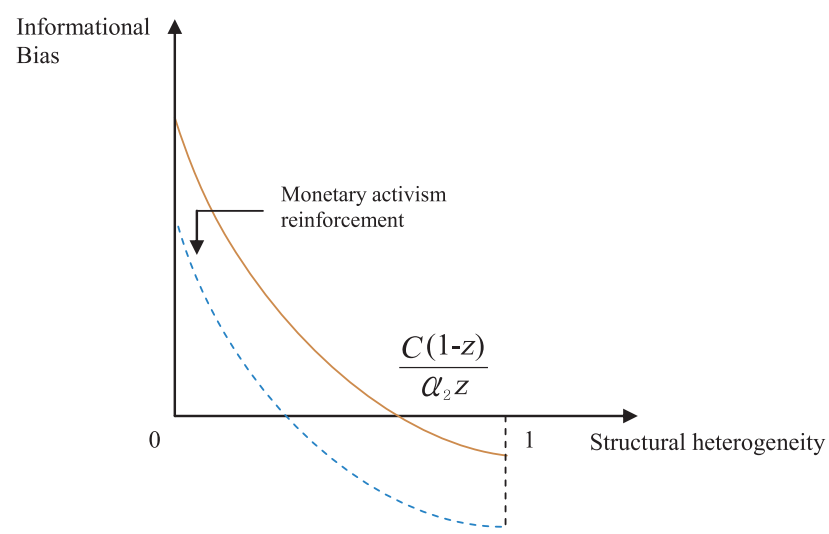

We can assume that government $i$ will act in this manner according to the principle we have already put forward: given the fact that the Central Bank and the governments work together in stabilizing demand shocks, the governments tamper with their information in order to make up for the central bank's possible loss of activism in taking stabilization measures. Indeed, if the union's heterogeneity increases at the level of the mechanisms of single monetary policy transmission ( $h$ increases), then the single monetary policy has a growing (decreasing) influence on country $i(j)$ and consequently the central bank's efforts to achieve stabilization are transmitted more fluently to country $i$ to the detriment of country $j$. Thus, when $h<\frac{C(1-z)}{\alpha_{2} z}$, country $i$ benefits greatly from stabilization undertaken by the central bank, which results in it having less reason to distort its information when $h$ rises. On the contrary, if structural heterogeneity becomes more important, country $i$ is inclined to lie about the type and the extent of its shock so that it could limit the variation of the union's aggregate values and avoid the detrimental effects of a monetary policy which is too active for this country.

Regarding country $j$, its communication strategy starts to differ from country $i$ 's with $h$ rising as country $j$ tries to make up for a slow-down of the single monetary policy's stabilization effects by gradually overestimating its shock. Exceptionally, there is a case in which the above mechanism doesn't apply and that is when positive spillovers $(b>0)$ occur while the level of heterogeneity is above a threshold value $\bar{h}\left(\bar{h}=\frac{C}{A}\right)$. In this case, government $j$ modifies the nature of its shock by introducing a distortion that decreases as $h$ rises (Figure 2). Indeed, in the case of symmetric shocks and positive spillovers, the country $j$ can count on its neighbour's stabilization efforts whose intensity is all the more important as the central bank's activism is low. Country $j$ will modify the information about the nature of its shock in order to make up for the effects of the shocks at the aggregate level and limit the central bank's intervention. To put it differently, if $h$ rises beyond the threshold value $\bar{h}$, country $j$ will benefit less and less from the stabilizing effects of monetary policy and it will attempt to neutralize the central bank's actions in order to take advantage its neighbours' reinforced fiscal activism. This exception doesn't 
occur if the fiscal spillovers are negative irrespective of the degree of structural heterogeneity within the union.

\section{Figure 2. Country $j$ 's Informational Bias in the case of Symmetrical Shocks}

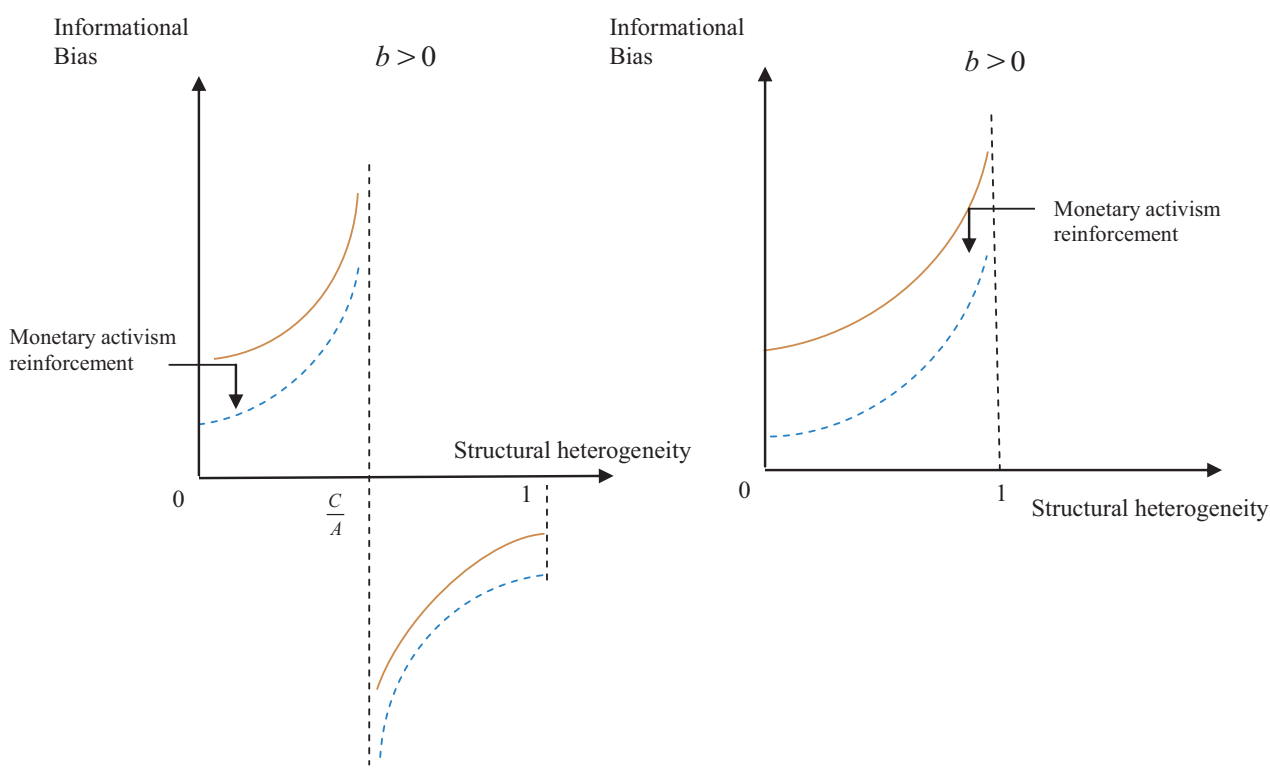

Regarding the governments' behaviour in the case of asymmetric shocks ${ }^{13}$, we can first notice that each of them is inclined to overestimate its specific shock so that the central bank would become more sensitive to its cyclical environment to the detriment of its neighbours.

The differences between the countries in terms of communication strategy can be accounted for by the mechanism analysed previously in the case of symmetric shocks: as $h$ rises, country $i$ is less and less inclined to modify its information as long as the central bank meets an important part of its stabilizations needs contrary to country $j$ which tries to make up for a decrease in the stabilising effects of the single monetary policy by gradually overestimating its shock. Compared to the previous case, country $i$ 's communication strategy doesn't present a breaking point, the informational bias merely decreases according to the union's heterogeneity degree (Figure 3). Instead, for country $j$, the communication mechanisms are roughly identical to those identified for symmetric shocks (Figure 2). We can equally notice the same exception as in the case of symmetric shocks when fiscal spillovers are positive $(b>0)$ and the degree of structural heterogeneity is above the threshold value $\bar{h}\left(\bar{h}=\frac{C}{A}\right)$. The mechanisms involved are different from those which account for symmetric shocks: in the case of asymmetric shocks, country $j$ modifies the nature of its shock in order to increase the variation of the union's ag-

\footnotetext{
${ }^{13}$ To simplify the analysis, we take into account the case in which the shocks are perfectly asymmetric $\left(\varepsilon_{i}=-\varepsilon_{j}\right)$. A graphical analysis of the intermediate situations (shocks imperfectly asymmetric) is provided in the appendix.
} 
gregate variables and therefore to reinforce the central bank's activism. When $h$ rises the single monetary policy is likely to have counterproductive effects on country $i$ which will have to conduct a reactive fiscal policy favourable to country $j$ on account of the positive value of fiscal spillovers.

Figure 3. Country $i$ 's Informational Bias in the case of Perfectly Asymmetrical Shocks

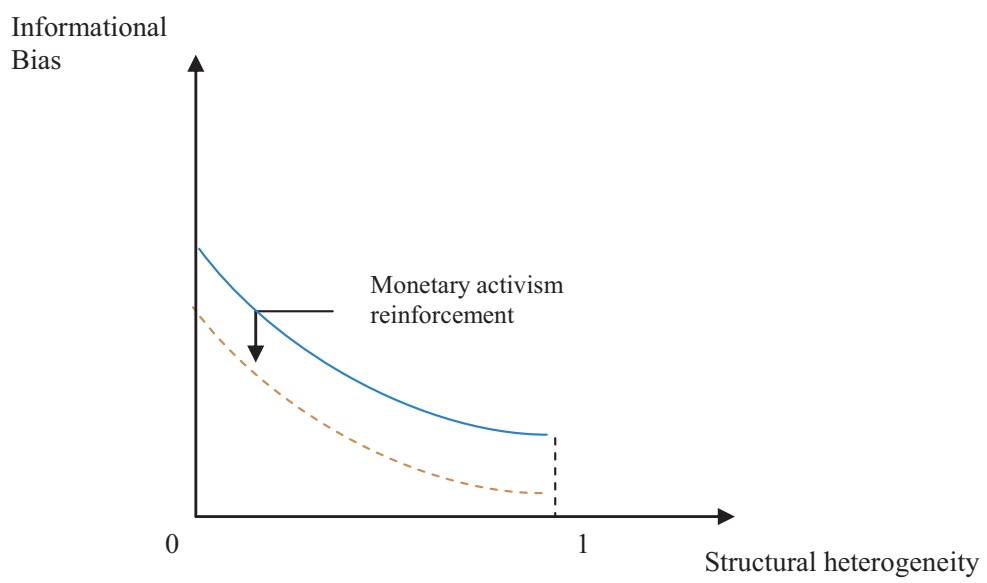

To sum up, we can point out that the governments are generally inclined to transmit inexact messages in order to influence the central bank's monetary policy. Indeed, for a revealing equilibrium to be reached, the conditions have to be extremely restrictive involving complete homogeneity at the union level and absolute monetary activism. When structural and/or cyclical heterogeneities exist, the governments tend to tamper with their private information in order to improve their own welfare. Therefore, a decentralized system of statistical data collection is unreliable and it may encourage the governments to communicate false information, thus reinforcing the union's informational asymmetry. The misleading behavior of the members could have serious consequences for a monetary union both within it, where the cohesion and the confidence of its members could be threatened, and without, where the union's institutions and the single currency could lose their credibility. In other words, this system of governance of a monetary union is likely to face a crisis of confidence on the part of member states, outside partners, and the market, which could have a negative effect on the growth and the development of the monetary union as a whole ${ }^{14}$. Under these circumstances, it becomes vital to tackle the issue of an institutional mechanism capable disciplining the governments and eliminating their motivation to modify their private information.

\footnotetext{
${ }^{14}$ The current debt crisis in the Euro zone is quite a significant example. Although the falsification of statistical data by the Greek government is not exclusively responsible for this crisis, there is general agreement on its catalyst role.
} 


\section{Incentive Institutional Mechanisms}

In order to avoid the problems caused by national governments' tampering with their private information, the simplest solution would be to create an independent institution which would gather each union member's statistical data. From a technical point of view, we can suppose that there may be institutions in the union that would have both the expertise and the necessary means to handle such centralized information gathering efficiently. Nevertheless, in practice, this situation may be difficult to realize because the centralized collection of the statistical data could be seen by the member countries as a loss of their independence and as a sign of lack of confidence in their capacity to collect and communicate reliable data, which could jeopardize the cohesion of the monetary union.

Another solution would be to revise the principle of subsidiarity in collecting statistical data. Thus, while the gathering of statistical data would be maintained at the national level, an optimum contract would be established to encourage the governments to reveal to the central bank exact information about their specific shocks. This optimal contract would have to be a "principal-agent" contract (Walsh (1995)) and would be included in the loss function of the fiscal authorities, annihilating their temptation to distort their private information.

If we suppose that the "principal's" objective is to reach a revealing equilibrium within the union, the "principal" will establish a contract that can require the "agent" to seek the optimum solution that will prevent it from distorting private information.

The fiscal authority, which is the "agent", will have its loss function modified by a linear contract that acts on its instrument of fiscal policy, i.e. the budget deficit.

The loss function of government $i$ is written as:

$$
L_{i}^{G}=\frac{1}{2}\left[\alpha_{1} y_{i}^{2}+\alpha_{2} g_{i}^{2}\right]+G_{i} g_{i}
$$

where $G_{i}$ is a linear penalty adapted to the fiscal authority of country $i$.

The optimum contract that will annihilate the government's temptation to modify the message sent to the central bank will be established before the shock takes place. The contract depends both on the message sent by the government to the central bank and on its neighbour's specific shock. Thus, in order to discipline the governments, the "principal" must endogenize the public authorities' communication strategies and impose certain constraints on the shocks of its neighbour, according to the principle described previously that the optimum announcement of a government is also dependent on the shock of its neighbour.

The equation for the optimal contract is obtained by a usual backward resolution and is written as:

$$
G_{i}=T_{i} \underline{\theta}_{i}+E_{i} \varepsilon_{j}
$$


Based on calculations ${ }^{15}$, we can identify two optimum contracts $G_{i 1}$ and $G_{i 2}$ corresponding to two values for the coefficients $T_{i}$ and $E_{i}$ :

$$
\begin{aligned}
& G_{i 1}=T_{i 1} \underline{\theta}_{i}+E_{i 1} \varepsilon_{j} \\
& G_{i 2}=T_{i 2} \underline{\theta}_{i}+E_{i 2} \varepsilon_{j}
\end{aligned}
$$

with $\quad T_{i 1}=\frac{S_{i}+\sqrt{S_{i}^{2}+4 F R_{i}\left(D-\alpha_{2} z h+C(1-z)\right)}}{2 F}$

$$
\underline{S_{i}-\sqrt{S_{i}+4 F R_{i}(D-\quad z h+C(1-z))}}
$$

$$
\begin{gathered}
E_{i 1}=\frac{\left[C(1-z)-\alpha_{2} z h-D\right]\left[R_{i}+\frac{a \alpha_{1}}{D C}\left(\frac{S_{i}+\sqrt{S_{i}^{2}+4 F R_{i}\left(D-\alpha_{2} z h+C(1-z)\right)}}{2 F}\right)\right]}{F\left(\frac{S_{i}+\sqrt{S_{i}^{2}+4 F R_{i}\left(D-\alpha_{2} z h+C(1-z)\right)}}{2 F}\right)+\frac{a \alpha_{1} \alpha_{2} z(C+A h)}{D A C}} \\
\left.E_{i 2}=\frac{\left[C(1-z)-\alpha_{2} z h-D\right]\left[R_{i}+\frac{a \alpha_{1}}{D C}\left(\frac{S_{i}-\sqrt{S_{i}^{2}+4 F R_{i}\left(D-\alpha_{2} z h+C(1-z)\right)}}{2 F}\right)\right]}{F\left(\frac{S_{i}-\sqrt{S_{i}^{2}+4 F R_{i}\left(D-\alpha_{2} z h+C(1-z)\right)}}{2 F}\right)+\frac{a \alpha_{1} \alpha_{2} z(C+A h)}{D A C}}\right)
\end{gathered}
$$

where $\quad S_{i}=\frac{a \alpha_{1}}{A C}\left[\frac{A\left(D-\alpha_{2} z h+C(1-z)\right)}{D}-\frac{\alpha_{2} z(C+A h)}{D}\right]$

$$
\begin{aligned}
& R_{i}=\frac{\alpha_{1} \alpha_{2}^{2} z(C+A h)\left(\alpha_{2}+\alpha_{1} a^{2}\right)}{A D^{2} C^{2}} \\
& F=\frac{4\left(a \alpha_{1} b\right)^{2}\left(\alpha_{2}+\alpha_{1} a^{2}\right)}{A^{2} C^{2}}
\end{aligned}
$$

If we apply the same principle to country $j$, we obtain two optimal contracts:

$$
\begin{aligned}
& G_{j 1}=T_{j 1} \underline{\theta}_{j}+E_{j 1} \varepsilon_{i} \\
& G_{j 2}=T_{j 2} \underline{\theta}_{j}+E_{j 2} \varepsilon_{i}
\end{aligned}
$$

\footnotetext{
${ }^{15}$ The detailed calculations that allow the identification of the solutions for the optimum contracts are available upon request.
} 
with : $\quad T_{j 1}=\frac{S_{j}+\sqrt{S_{j}^{2}+4 F R_{j}\left(D+\alpha_{2} z h+C(1-z)\right)}}{2 F}$

$$
\begin{aligned}
T_{j 2}= & \frac{S_{j}-\sqrt{S_{j}^{2}+4 F R_{j}\left(D+\alpha_{2} z h+C(1-z)\right)}}{2 F} \\
E_{j 1} & =\frac{\left[C(1-z)+\alpha_{2} z h-D\right]\left[R_{j}+\frac{a \alpha_{1}}{D C}\left(\frac{S_{j}+\sqrt{S_{j}^{2}+4 F R_{j}\left(D+\alpha_{2} z h+C(1-z)\right)}}{2 F}\right)\right]}{F\left(\frac{S_{j}+\sqrt{S_{j}^{2}+4 F R_{j}\left(D+\alpha_{2} z h+C(1-z)\right)}}{2 F}\right)+\frac{a \alpha_{1} \alpha_{2} z(C-A h)}{D A C}}
\end{aligned}
$$

$$
E_{j 2}=\frac{\left[C(1-z)+\alpha_{2} z h-D\right]\left[R_{j}-\frac{a \alpha_{1}}{D C}\left(\frac{S_{j}-\sqrt{S_{j}^{2}+4 F R_{j}\left(D-\alpha_{2} z h+C(1-z)\right)}}{2 F}\right)\right]}{F\left(\frac{S_{j}-\sqrt{S_{j}^{2}+4 F R_{j}\left(D-\alpha_{2} z h+C(1-z)\right)}}{2 F}\right)+\frac{a \alpha_{1} \alpha_{2} z(C-A h)}{D A C}}
$$

where: $S_{j}=\frac{a \alpha_{1}}{A C}\left[\frac{A\left(D+\alpha_{2} z h+C(1-z)\right)}{D}-\frac{\alpha_{2} z(C-A h)}{D}\right]$

$R_{j}=\frac{\alpha_{1} \alpha_{2}^{2} z(C-A h)\left(\alpha_{2}+\alpha_{1} a^{2}\right)}{A D^{2} C^{2}}$

We can note that such contracts involve both rules and discretion. Indeed, discretion preserves the governments' right to react to economic shocks while the rules force fiscal authorities to reveal the true information about their national economic shocks.

The question that may arise when adopting an optimal contract of this type is that of the identity of the "principal" as the authority able to influence the governments' behaviour by encouraging them to reveal their true information to the central bank. The "principal" must be a supranational authority, that defends the general interests of the union and which is likely to act on behalf of the union's stability and cohesion ${ }^{16}$ in order to obtain a revealing equilibrium within the union.

Another institutional means that may allow for a revealing equilibrium within the union could be to fight against one of the direct causes triggering the governments' deceitful behaviour. One of these causes could be the extreme rigidity of the policy-mix in the monetary

\footnotetext{
${ }^{16}$ Based on the idea stated earlier that changing information may be harmful to the stability of the Union, an incentive contract can only be effective if the supranational authority explicitly defines as an objective on its agenda the necessity to survey the governments' behavior.
} 
union which diminishes the capacity of the governments to fight against economic shocks. The governments would be undoubtedly less tempted to distort their messages to the central bank if monetary policy were more reactive to national cyclical evolutions. We can thus imagine a situation in which the single central bank's objectives could be reviewed by weighting interest in price aggregate stability with an appropriate concern about the evolution of growth and employment at the national level ${ }^{17}$. If we go further with this recommendation, an institutional solution that could facilitate the emergence of a revealing equilibrium could be enhanced cooperation between fiscal authorities within the union. Obviously, one cannot achieve full coordination between all union members, since it is difficult to identify common interests between countries that are structurally and cyclically heterogeneous. Nevertheless, it is highly possible to achieve a variable geometry fiscal coordination ${ }^{18}$ since it is more easier to decide on common actions to take within a small group of relatively homogeneous countries than at a global level. Due to its flexibility and taking into account heterogeneity within the union, such a mechanism could therefore be an appropriate institutional solution insuring better protection against economic shocks and stifling considerably the governments' temptation to lie.

To sum up, the institutional solutions that can discipline the governments have a common feature: their supranational dimension. The major advantage of this supranational solution relies on the fact that it is capable of better aligning the objectives of the various policymakers. From a supranational perspective, the institutional solutions are of two types: control solutions and cooperation solutions. The first type of solution relies on an incentive contract drawn up by a supranational authority and which is legitimated by a clear definition of the objectives of stability and of cohesion in the monetary union, objectives which must be accepted by all union members. The supranational feature of the second type of solution relies on the idea of cooperation between policymakers, which implies defining common objectives for these public authorities. Even though fiscal federalism is not likely to be a satisfactory solution for the member countries, which could be very attached to their national independence, other solutions, involving a convergence of macroeconomic objectives, may be taken into account, for instance: reinforced fiscal cooperation or a single monetary policy which pay more attention to the output evolution of the member countries of the union.

\footnotetext{
${ }^{17}$ It should be taken into account that national economic evolution in the member countries doesn't mean that the central bank is losing some of its independence. It is merely increasing the complexity of its objective function which could be thus more appropriate to the current macroeconomic context.

${ }^{18}$ See Jacquet and Pisani-Ferry (2000), Oros (2008b), Pisani-Ferry (1997) for an analysis of the idea of variable geometry fiscal coordination in the case of the Euro zone.
} 


\section{Conclusion}

In this paper, we have analysed the impact in terms of macroeconomic stabilization of a form of asymmetrical information between the countries of a heterogeneous monetary union. Considering the heterogeneity of the union with respect both to the mechanisms of monetary policy transmission and to the nature of the shocks affecting union members, we have assumed that the countries have private information about their specific shocks. We have thus examined whether the governments are inclined to take advantage of this information gap in order to indirectly influence the central bank in its choice of monetary policy.

We have proved that without perfect homogeneity within the union and absolute monetary activism, the governments are constantly inclined to distort their messages to the central bank. Nevertheless, this opportunist behaviour, which is largely dependent on the nature of the shocks and on the extent of the union's structural heterogeneity, is not linear, the optimum communication strategies being affected by threshold effects.

At the institutional level, the results have shown the limits of the subsidiarity principle in collecting statistical data in a heterogeneous monetary union. We have suggested several solutions to be studied in order to persuade the governments not to adopt deceitful behaviour with regard to the single central bank when communicating private information on their economic shocks: adopting an incentive principal-agent contract between the policymakers of the union; making the single monetary policy more reactive to cyclical asymmetries between the union member countries; adopting reinforced fiscal coordination at the level of a group of more homogeneous countries.

The framework that we have adopted in this article can be further developed, firstly by extending the model to supply shocks. Since they can have opposite effects on output and inflation, it is likely that a conflict of interests arises between the governments and the central bank when it comes to neutralizing the impact of these shocks. Convergence of stabilization efforts made by policymakers in the case of demand shocks could be replaced, in the case of supply shocks, by a divergence of the stabilization efforts of the fiscal and monetary authorities (Oros (2008a). The opposing convergence-divergence in efforts to stabilize demand and supply shocks will very likely influence the governments' mechanisms of strategic communication.

Secondly, our current model could also be developed by analysing the governments' strategic behaviour in a dynamic framework involving a repeated game between policymakers. More exactly, we could analyse the governments' optimum announcements if we suppose that the authorities are able to keep track of previous economic policy decisions and are sensitive to issues of credibility and reputation linked to their own decisions regarding economic policy.

Received 26 July 2011, Revised 11 June 2012, Accepted 25 July 2012 


\section{References}

Beetsma, R., Bovenberg, L. (1998) Monetary Unification without Fiscal Coordination may Discipline PolicyMakers, Journal of International Economics, 45(2), 239-258.

Beetsma, R., Bovenberg, L. (1999) Does Monetary Unification Lead to Excessive Debt Accumulation?, Journal of Public Economics, 74(3), 299-325.

Beetsma, R., Debrun X., Klaassen F. (2001) Is Fiscal Policy Coordination in EMU Desirable?, Swedish Economic Policy Review, 8, 57-98.

Beetsma, R., Uhlig, H. (1999) An Analysis of the Stability and Growth Pact, The Economic Journal, 109, 546571.

Bottazzi, L., Manasse, P. (1998) Bankers' Versus Workers' Europe (I): Asymmetric Information in EMU, IGIER Working Paper, 127.

Bottazzi, L., Manasse, P. (2005) Asymmetric Information and Monetary Policy in Common Currency Areas, Journal of Money, Credit and Banking, 37(4), 603-621.

Chari, V.V., Kehoe, P. (1998) On the Need for Fiscal Constraints in a Monetary Union, Federal Reserve Bank of Minneapolis Working Paper, 387.

Crettez B. (1998) Le système d'informations économiques d'une Banque centrale européenne et le principe de subsidiarité, Revue Economique, 49(4), 989-1003.

Dixit, A., Lambertini, L. (2001) Monetary-fiscal Policy Interactions and Commitment Versus Discretion in a Monetary Union, European Economic Review, 45(4-6), 977-987.

Dornbusch, R. (1997) Fiscal Aspects of Monetary Integration, American Economic Review, 87(2), 221-223.

Duchassaing, S., Koessler, F. (2004) Coordination des politiques budgétaires et monétaires dans l'UEM en présence de chocs et d'informations asymétriques, Revue Economique, 1, 5-20.

Engwerda, J., Plasmans, J., Van Aarle, B. (2002) Cooperative and Non-Cooperative Fiscal Stabilization Policies in the EMU, Journal of Economic Dynamics and Control, 3, 451-481.

Mathieu, B. (2009) Tripatouiller les statistiques, la sale manie du gouvernement, l'Expansion, $1^{\mathrm{er}}$ mai.

Meillassoux, M. (2011) Chômage: la face cachée du "miracle économique allemand", Myeurop.info, 4 octobre.

Mundschenk, S., Von Hagen, J. (2003) Fiscal and Monetary Policy Coordination in EMU, International Journal of Finance and Economics, 4, 279-295.

Oros, C. (2008a) Macroeconomic Stabilization in a Heterogeneous Monetary Union: Some Insights into the Effects of Fiscal Policy Coordination, Economics Bulletin, 5(34), 1-12.

Oros, C. (2008b) Coordination budgétaire à géométrie variable et stabilisation conjoncturelle dans une Union monétaire hétérogène, Economie Appliquée, LXI(3), 99-132.

Uhlig, H. (2002) One Money but Many Fiscal Policies in Europe: What Are the Consequences?, CEPR Discussion Papers, 3296.

Villieu, P. (2003) Pacte de stabilité, crédibilité du policy-mix et coordination des politiques budgétaires en union monétaire, Revue Economique, 1, 25-46. 


\section{Appendices}

We represent informational bias in the same figure for the two opposite cases:

- symmetrical shocks $\left(\varepsilon_{i}=\varepsilon_{j}\right)$ - a continuous line curve (S)

- perfectly asymmetrical shocks $\left(\varepsilon_{i}=-\varepsilon_{j}\right)$ - a dotted line curve (AS).

Starting with the curve of the symmetrical shocks, the informational bias curve moves from the curve $\mathrm{S}$ to the curve AS as the shocks' degree of asymmetry grows, and it reaches the curve AS in the case of perfect asymmetry between the shocks. To put it differently, in the case of imperfectly asymmetrical shocks, the informational bias is placed between the two curves represented in the Figures A1-2.

The two countries' informational biases are represented below. The relative position of these biases according to the nature of the shocks depends on the sign and the extent of fiscal spillovers (parameter $b$ ).

Figure A1. Country $i$ 's Informational Bias

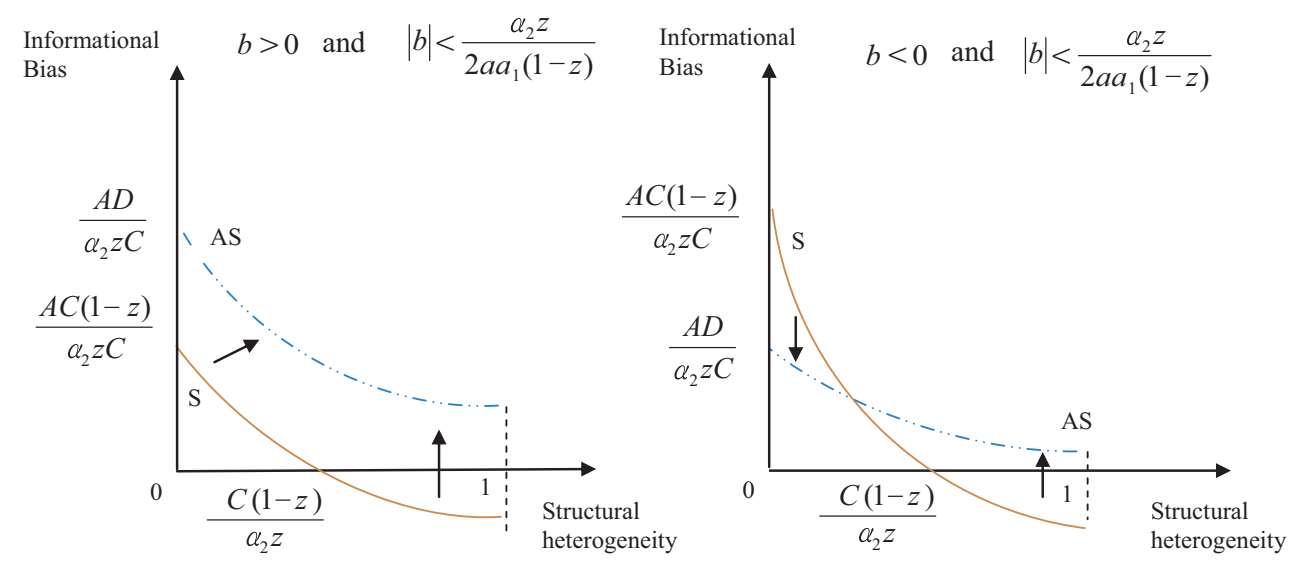


Figure A2. Country $i$ 's Informational Bias
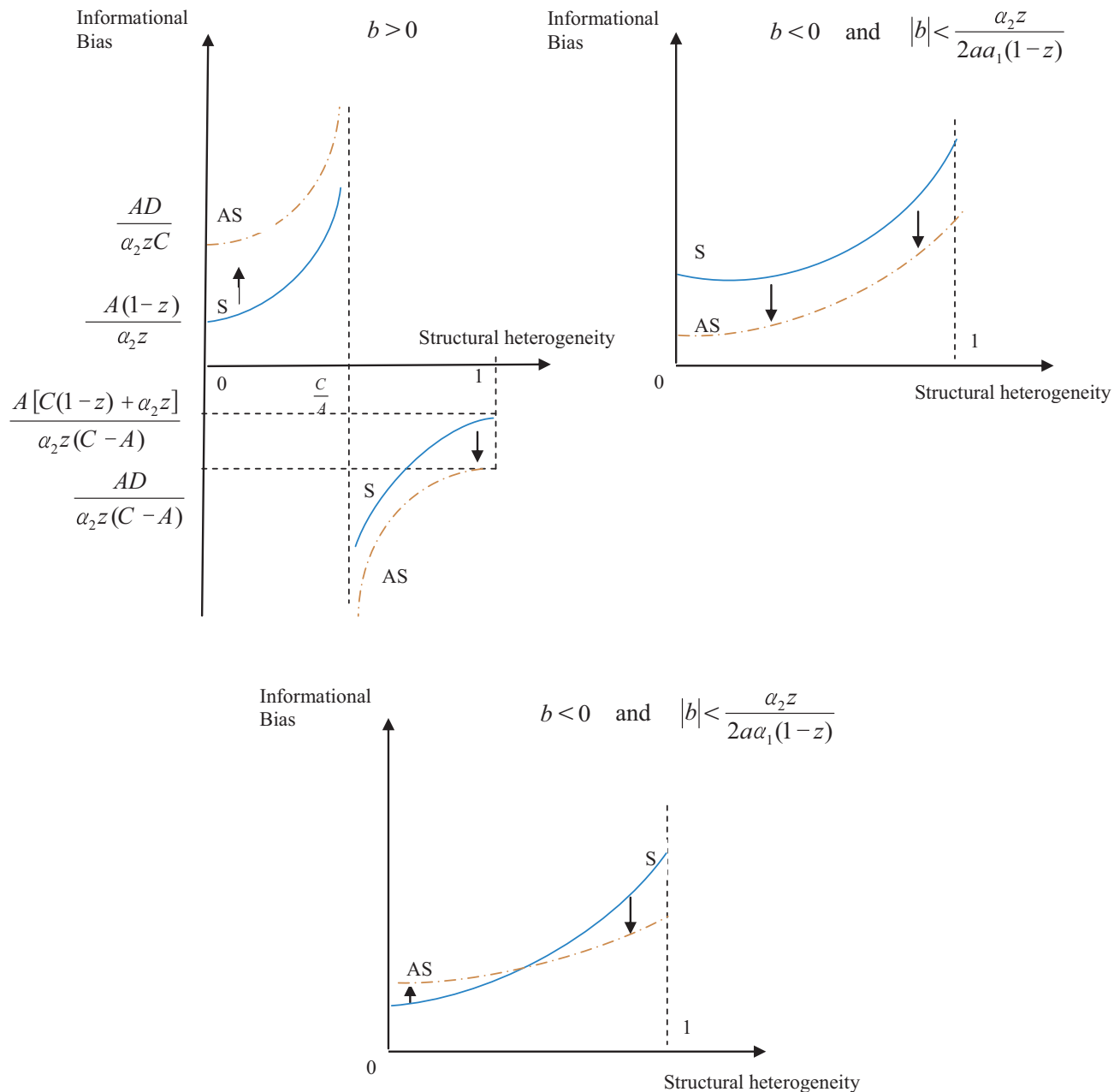
